\title{
Complete regression of advanced prostate cancer for ten years: A case report and review of the literature
}

\author{
BING YAN, XIANZE MENG, XIAOWEI WANG, PINKANG WEI and ZHIFENG QIN \\ Department of Traditional Chinese Medicine, Shanghai Changzheng Hospital, \\ Second Military Medical University, Shanghai 200003, P.R. China
}

Received January 19, 2013; Accepted May 30, 2013

DOI: $10.3892 / \mathrm{ol} .2013 .1377$

\begin{abstract}
Long-term complete regression of prostate cancer (PCa) is a rare phenomenon. The current report presents the case of an advanced PCa patient with rare clinical features. Following the generation of a definitive diagnosis, the patient was administered with flutamide treatment ( $0.25 \mathrm{~g}$ flutamide) 3 times a day, for 5 consecutive years, prior to surgical castration. Following surgery, $3.75 \mathrm{mg}$ enantone was injected (i.h.) once per month for 3 months, without suspending the flutamide treatment. In addition, traditional Chinese herbal medicine was administrated immediately following surgery. Strontium-89 radiotherapy was performed for multiple bone metastases, and the multiple metastatic lesions (lung and bone) of the individual disappeared in $<7$ months. The patient has currently survived for $>10$ years with no development of castration resistance or signs of recurrence. Nadir prostate-specific antigen (PSA) levels had remained at $<0.1 \mathrm{ng} / \mathrm{ml}$ following the initial treatment, and the erythrocyte sedimentation rate (ESR) value was high and had been observed to fluctuate during the treatment. The present case report considers the role of the androgen-receptor in $\mathrm{PCa}$ and indicates that careful interpretation of nadir PSA and ESR levels may aid in the prediction of patient prognosis.
\end{abstract}

\section{Introduction}

Prostate cancer ( $\mathrm{PCa}$ ) is the second leading cause of mortality in the western world, but the single most common non-cutaneous malignancy in the United States, with $\sim 241,740$ and $\sim 28,170$, morbidities and mortalities, respectively, in 2012 (1,2). Despite an increase in available reagents for PCa treatment (3-5), the prognosis for advanced-stage

Correspondence to: Dr Zhifeng Qin, Department of Traditional Chinese Medicine, Changzheng Hospital, Second Military Medical University, 415 Fengyang Road, Shanghai 200003, P.R. China E-mail: yanbing3741@gmail.com

Key words: complete regression, erythrocyte sedimentation rate, prostate specific antigen, traditional Chinese herbal medicine, prostate cancer patients remains discouraging, with a median life expectancy of $\sim 2.5$ years (6). Long-term complete regression of $\mathrm{PCa}$ is uncommon and the complex mechanisms involved in advanced PCa are not yet understood. The current report presents the case of a patient with stage IV $\mathrm{PCa}$, with rare clinical features, indicating a role for the androgen-receptor in PCa. Written informed consent was obtained from the patient.

\section{Case report}

Patient presentation and diagnosis. A 51-year-old male with progressive weakness, dull shoulder and back pain and low-grade fevers in the afternoon (range, 37.7-38. $3^{\circ} \mathrm{C}$ ) was referred to Shanghai Changzheng Hospital (Shanghai, China) in November, 2002. Two months previously, the individual detected a mass in the right groin, which was pliable in texture with no pain upon the addition of pressure. A physical examination revealed a $2 \times 2-\mathrm{cm}$ mass in the right groin. Blood pressure, pulse and body temperature values were all within the normal range. ECG results were normal, as were results from blood and fecal tests. Prostate-specific antigen (PSA) tumor marker levels were $>500 \mathrm{ng} / \mathrm{ml}$ (reference value, $0-35 \mathrm{ng} / \mathrm{ml}$ ), however, other tumor markers, including $\alpha$-fetoprotein (AFP), carcinoembryonic antigen (CEA), carbohydrate antigen (CA)19-9, CA12-5 and neuron-specific enolase (NSE) remained within the normal ranges. The erythrocyte sedimentation rate (ESR) was $45 \mathrm{~mm} / \mathrm{h}$ and the anti-streptolysin ' $\mathrm{O}$ ' and anti-rheumatoid factor test results were negative. MRI of the pelvis and the lumbar spine detected an enlarged prostate with non-uniform signals at the bottom of the peripheral ribbon, multiple infiltrating lesions in the lumbar, sacrum, pelvis and bilateral thighbone, a T11-12 intraspinal tumor and soft tissue nodules in the right groin (Fig. 1). A bone scan revealed multiple skeletal metastases (Fig. 2A) and a chest radiograph and lung MRI identified a 3x2-cm lobulated node in the right hilum (Fig. 3A and B). A review of the patient's medical history showed the individual had suffered from lumbar disk disease (T5-S1) for 8 years, in addition to a long-term history of smoking and alcohol use. The patient was diagnosed with advanced prostatic cancer (IV, cT4N2M1c) following an ultrasonographic-guided biopsy performed in November, 2002. Pathology results identified rounded cells with enlarged nuclei and an irregular gland shape, which were deeply stained and infiltrated the normal tissue (Fig. 4). 

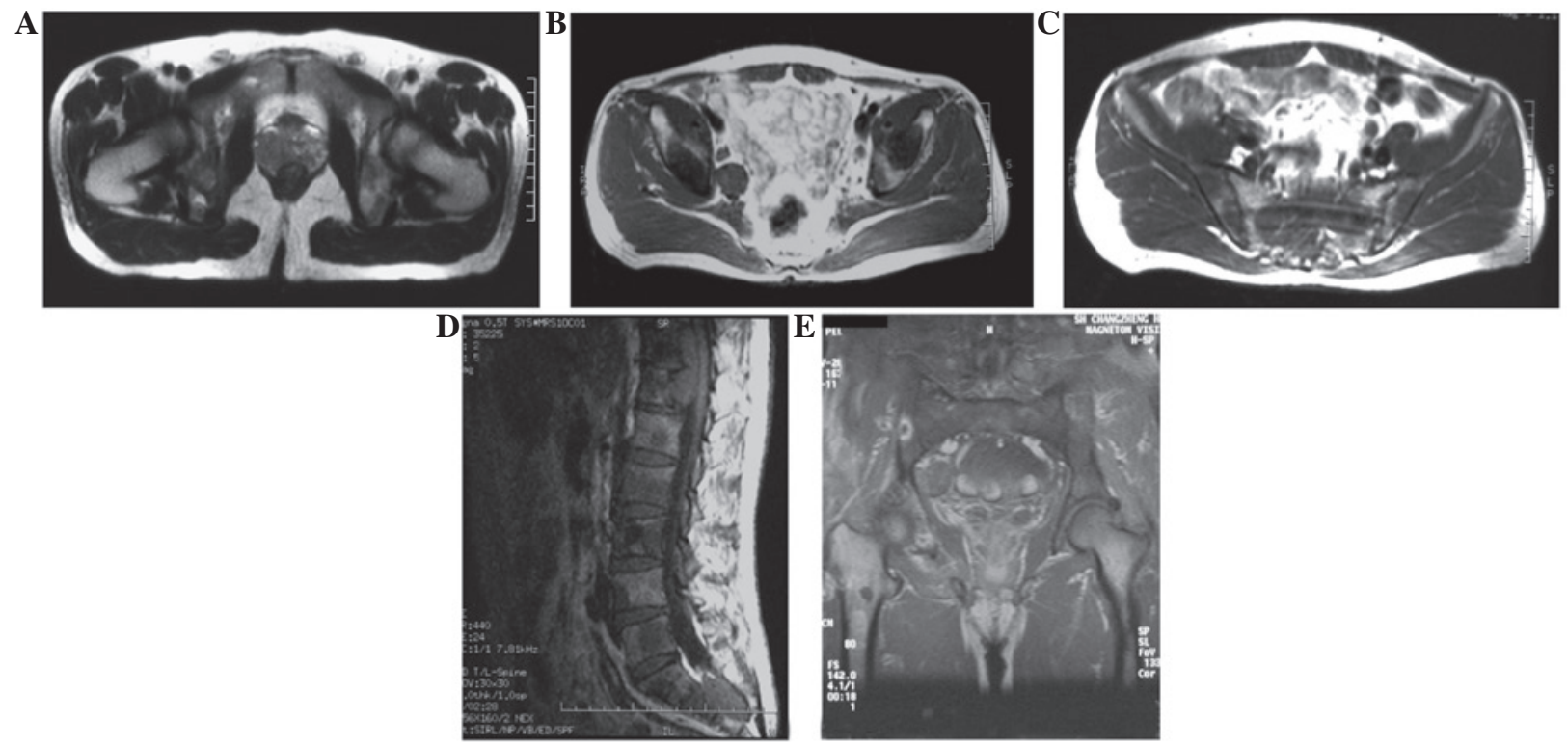

Figure 1. MRI of pelvis and lumbar spine (T1 weight). (A) Slightly increased prostate volume, with a less smooth fringe and non-uniform signal at the bottom of the peripheral ribbon. (B) Soft tissue nodules in the right groin. (C) Bilateral ilium showing a low signal, notably on the right. (D and E) T11-12 intraspinal tumor and bilateral thigh bone detecting low signals.
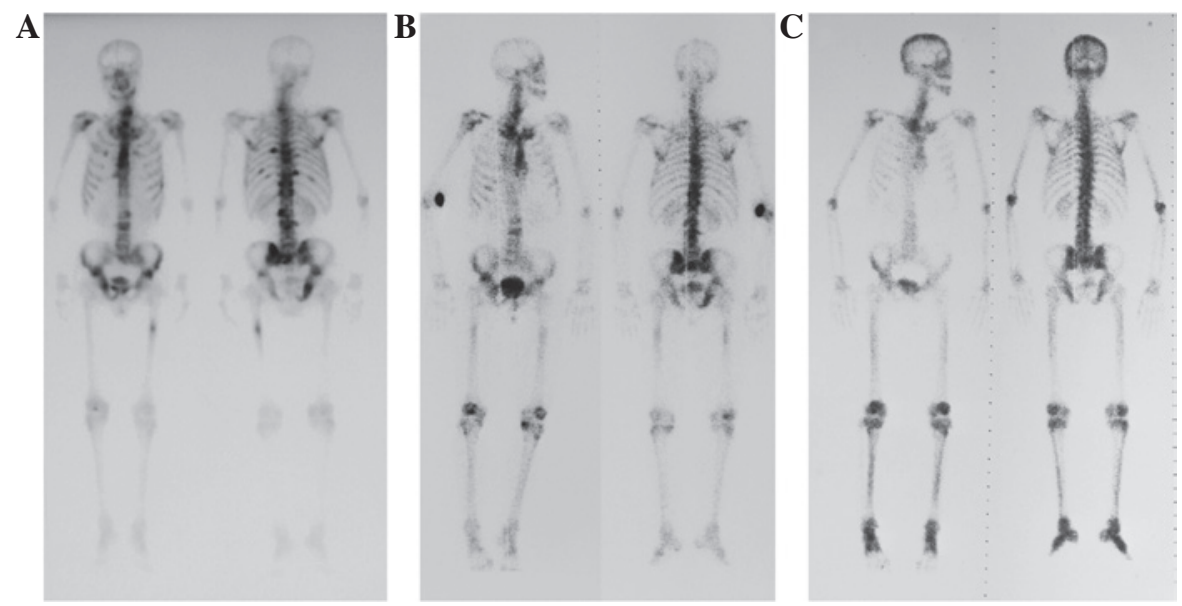

Figure 2. Patient bone scans. (A) Multiple skeletal metastases apparent in ribs, lumbar spine and bilateral ilium (November, 2002). (B) Evident shrinking of bone metastasis with the exception of the lumbar spine (26 March 2003) (C) Complete remission of bone metastasis (June 24, 2003).

Table I. Ingredients of the traditional Chinese herbal medicine.

\begin{tabular}{llr}
\hline Chinese name & \multicolumn{1}{c}{ Latin name } & $\%$ \\
\hline Huangqi & Astragali Radix & 13.51 \\
Taizishen & Pseudostellariae Radix & 13.51 \\
Nvzhenzi & Ligustri Lucidi Fructus & 13.51 \\
Gouqi & Lycii Fructus & 6.75 \\
Biejia & Trionycis Carapax & 4.50 \\
QuanXie & Scorpio & 2.70 \\
Wugong & Scolopendra & 4.50 \\
Tianlong & Gekko Chinensis & 6.75 \\
Dilong & Pheretima & 6.75 \\
Banbianlian & Lobeliae Chinensis Herba & 6.75 \\
Banzhilian & Scutellariae Barbatae Herba & 6.75 \\
Jineijin & Galli Gigerii Endothelium Corneum & 6.75 \\
Dazao & Jujubae Fructus & 4.50 \\
Gancao & Glycyrrhizae Radix Et Rhizoma & 2.70 \\
\hline
\end{tabular}

Treatment and clinical course. Flutamide $(0.25 \mathrm{~g})$ was administered (p.o.) 3 times a day prior to surgical castration in December 2002. In addition, $3.75 \mathrm{mg}$ enantone was injected (i.h.) once every month, for 3 months, without suspending the flutamide treatment. A traditional Chinese herbal medicine (TCHM) was administrated immediately following surgery and at follow-up appointments (Table I). In January 2003, strontium-89 radiotherapy for multiple bone metastases was performed. Laboratory tests at that time indicated a significant decrease in PSA levels to $0.32 \mathrm{ng} / \mathrm{ml}$, which had reached $0.03 \mathrm{ng} / \mathrm{ml}$ at the end of the month. In addition, a chest radiograph identified that the lung lesion had gone (Fig. 3C). In March 2003, a repeat chest radiograph, which detected no abnormalities, was performed and a bone scan demonstrated a marked reduction of bone metastasis (Fig. 2B). Upon first admission, the patient exhibited levels of ESR that fluctuated above normal (Fig. 5), while the PSA levels remained at $<0.1 \mathrm{ng} / \mathrm{ml}$. In June 2003, an additional bone scan revealed 
Table II. Results of published case reports of the regression of metastasis in prostate cancer.

\begin{tabular}{|c|c|c|c|c|c|}
\hline First author/s (ref) & $\begin{array}{c}\text { No. of } \\
\text { cases }\end{array}$ & $\begin{array}{l}\text { Location of } \\
\text { metastasis }\end{array}$ & $\begin{array}{l}\text { Evidence of } \\
\text { regression }\end{array}$ & Management & Follow-up record \\
\hline Peyrí Rey (7) & 1 & Bone & Bone scan & ADT & NA \\
\hline Kumar et al (8) & 1 & Eye & Not available & Hormonal therapy & NA \\
\hline Hoshi et al (9) & 1 & Bone & Bone scan & $\begin{array}{l}\text { Cisplatin, UFT, dexamethasone, } \\
\text { diethylstilbestrol diphosphate }\end{array}$ & NA \\
\hline Weiss et al (10) & 1 & Bone & Scintigraphy & Surgery/153Sm-EDTMP & NA \\
\hline Ameur et al (11) & 1 & Brain & NA & NA & Recurrence \\
\hline Gayet and Curtillet (12) & NA & Lung & NA & NA & NA \\
\hline Turner and Chaudhary (13) & 1 & Bone & PSA/Imaging & Alternative therapies & NA \\
\hline
\end{tabular}

ADT, androgen deprivation therapy; 153Sm-EDTMP, Samarium-153-ethylene diamine tetramethylene phosphonate; UFT, tegafur-uracil; PSA, prostate-specific antigen; NA, not available.

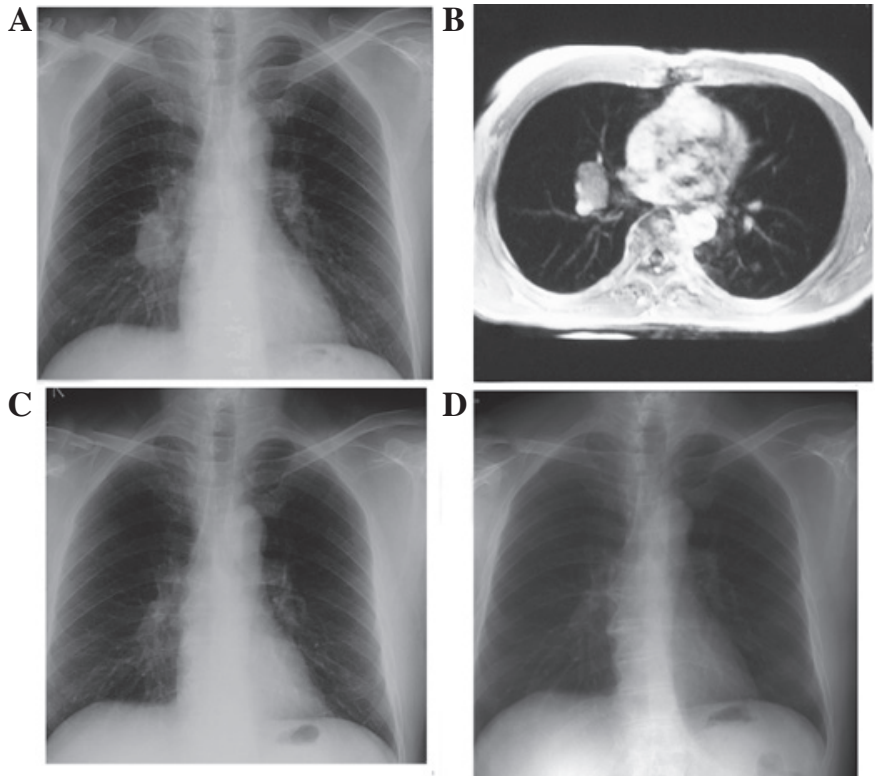

Figure 3. Chest radiograph and MRI of the lungs. (A) Chest radiograph identifiying a lesion in the right hilus pulmonis with a clear edge (November 26, 2002). (B) MRI identifying a $3 \times 2-\mathrm{cm}$ lobulated node in the right hilum (November 26, 2002). (C) Chest radiograph detecting no mass, but indicating the presence of a chaotic blood vessel system (December 29, 2002). (D) Normal chest radiograph (December 20, 2012).

complete remission of the bone metastasis (Fig. 2C). Annual bone scans continued to confirm this result until the scans were stopped in June 2005.

The administration of flutamide was withdrawn in May 2007, but the use of TCHM was continued; no adverse effects were identified by the individual, with the exception of controllable hot flushes. However, no recurrence was detected at the annual follow-up appointments. During treatment, blood, urine, stool, electrolyte, biochemistry, tumor marker and hemagglutinin tests were performed and demonstrated to be within the normal ranges. When CT or MRI scans were not performed at the patient's follow up appointments, a visceral ultrasound examination, including an examination of the prostate, was arranged and no abnormalities were detected. The patient's most recent appointment was in December 2012, where a physical examination and a chest radiograph detected

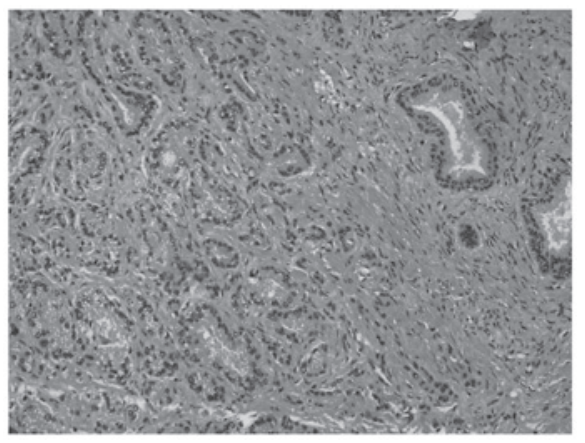

Figure 4. Pathology results for the prostate. Rounded cells with enlarged nuclei and an irregular gland shape, deeply stained and infiltrating the normal tissue.

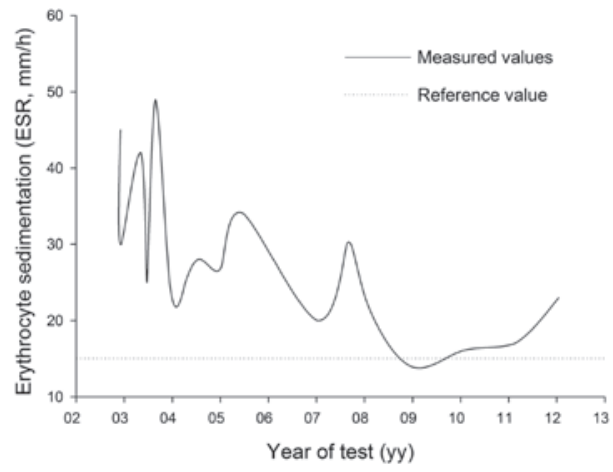

Figure 5. Fluctuation of erythrocyte sedimentation rate (ESR). High values were detected between 2002 and 2012, with the exception of between 2008 and 2010.

no abnormalities (Fig. 3D). An examination of the liver, gall bladder, pancreas, spleen, kidney, prostate, bladder and the lymph nodes of the bilateral groin was performed by abdominal ultrasound and were all identified to be normal. PSA and ESR levels were $0.06 \mathrm{ng} / \mathrm{ml}$ and $25 \mathrm{~mm} / \mathrm{h}$, respectively.

\section{Discussion}

According to the international system for staging $\mathrm{PCa}$, the present case was classified as clinical stage IV (cT4N1M1c) PCa. Few studies of the regression of PCa metastasis have been published and the majority describe single lesions with 
no records of long-term follow-up (Table II) (7-13). Therefore, in this regard, the present case is unique.

The cellular and molecular events underlying the development of PCa are not yet understood, but it has been demonstrated that the role that androgens play is significant and, as a result, anti-androgen therapy is the preferred treatment. For previously untreated and advanced PCa, antiandrogen monotherapies, including flutamide therapy, has been reported to be effective $(14,15)$. However, only single androgen deprivation therapy (ADT) is recommended by the National Comprehensive Cancer Network (2011) for M1 patients, based on the evidence that combined- or triple-androgen blockage represents no survival benefit over castration alone (16). In the present case report, the treatment regimens conflicted with the treatment guidelines and recommendations for $\mathrm{PCa}$, and the reason for the final notable results remains currently unclear. The majority of advanced PCa cases are initially sensitive to ADT, however, the magnitude of castration-induced primary regression does not predict clinical outcome (17) and patients generally develop castration resistance within a median time of 12-18 months (18). Treatment of castration-resistant PCa (CRPC) is challenging since growth of the cancer at this stage is hypothesized to be regulated by androgens, and mutations of the androgen-receptor (AR) genes are common $(19,20)$. However, previous studies have indicated that the AR remains a significant target in patients with CRPC (21). Although results of the current case report are unclear, based on the management and clinical presentation, it may be hypothesized that androgens play a significant role in $\mathrm{PCa}$.

Advances in molecular biomarkers have developed prognostic factors, allowing for improved identification of patients likely to benefit from a specific reagent and are therefore essential for selecting treatments. PSA is a well-established marker for monitoring treatment response and disease recurrence $(22,23)$. Various parameters of PSA have been studied $(24,25)$ for example, a nadir PSA of $<4 \mathrm{ng} / \mathrm{ml}$ within 6-7 months following initial treatment has been identified to be a significant predictor of the progression time to CRPC and overall survival $(24,26)$. Previous studies have demonstrated that $40-50 \mathrm{~mm} / \mathrm{h}$ ESR at diagnosis is a marker for low-risk cancer-specific mortality (27). The present patient had a nadir PSA of $0.1 \mathrm{ng} / \mathrm{ml}$ at 2 months after the treatment, which remained low at the follow-up appointments. In addition, ESR was $45 \mathrm{~mm} / \mathrm{h}$ at diagnosis. We hypothesize that these features indicate an improved prognosis. Other prognostic factors, including circulating tumor cells, have also been demonstrated as useful for predicting survival benefit following treatment for metastatic CRPC and hormone-sensitive PCa $(28,29)$, however, results have yet to be confirmed and validated by future studies (30).

Alternative medicine is popular among cancer patients and previous studies have demonstrated that $8.4-26.5 \%$ of PCa patients use herbal remedies $(31,32)$. TCHMs, including Realgar-Indigo naturalis and PHY906, are some of the most popular remedies and have been scientifically proven to be effective for cancer management (33-35). Results indicating that TCHMs may lead to the complete regression of cancer have been obtained in lung cancer and hepatocellular carcinoma $(36,37)$. In the present case report, a TCHM was taken at the onset of treatment and then consistently for 4 years.
Although it is hypothesized that the withdrawal of flutamide may induce a reduction of PSA in $40 \%$ of PCa patients (38), no rebound of PSA or recurrence was identified, therefore, TCHM may have a certain treatment value. The efficacy of TCHM cannot be defined in patients based on the current case report and no conclusive evidence has been obtained from randomized trials. However, the current study and others have indicated that TCHM may be an effective option for the future management of PCa.

Overall, the present case report demonstrates a role for the androgen-receptor in PCa and indicates that the careful interpretation of nadir PSA and ESR may effectively predict patient prognosis in the future.

\section{References}

1. Siegel R, Naishadham D and Jemal A: Cancer Statistics, 2012. CA Cancer J Clin 62: 10-29, 2012.

2. Boyle P and Ferlay J: Cancer incidence and mortality in Europe 2004. Ann Oncol 16: 481-488, 2005.

3. Attard G, Reid AH, Yap TA, Raynaud F, Dowsett M, Settatree S, Barrett M, Parker C, Martins V, Folkerd E, Clark J, Cooper CS, Kaye SB, Dearnaley D, Lee G and de Bono JS: Phase I clinical trial of a selective inhibitor of CYP17, abiraterone acetate, confirms that castration-resistant prostate cancer commonly remains hormone driven. J Clin Oncol 26: 4563-4571, 2008.

4. Kantoff PW, Higano CS, Shore ND, Berger ER, Small EJ, Penson DF, Redfern CH, Ferrari AC, Dreicer R, Sims RB, et al; IMPACT Study Investigators: Sipuleucel-T immunotherapy for castration-resistant prostate cancer. N Engl J Med 363: 411-422, 2010.

5. Pezaro C and Attard G: Prostate cancer in 2011: redefining the therapeutic landscape for CRPC. Nat Rev Urol 9: 63-64, 2012.

6. Aus G, Robinson D, Rosell J, Sandblom G and Varenhorst E; South-East Region Prostate Cancer Group: Survival in prostate cancer outcomes from a prospective, population-based cohort of 8887 men with up to 15 years of follow-up: results from three countries in the population-based National Prostate Cancer Registry of Sweden. Cancer 103: 943-951, 2005.

7. Peyrí Rey E: Regression bone metastases in patient with prostatic cancer. Actas Urol Esp 32: 1050, 2008 (In Spanish).

8. Kumar P, Duarte J and Pati J: Metastatic prostate cancer presenting as diplopia with regression of signs with hormone manipulation. Br J Hosp Med (Lond) 66: 646, 2005.

9. Hoshi S, Ohyama C, Hagisawa S, Ono K, Satoh M, Saito S, Fukuzaki A and Arai Y: Complete regression of bone metastases on super bone scan, by low-dose cisplatin, UFT, diethylstilbestrol diphosphate, and dexamethasone in a patient with hormone-refractory prostate cancer. Int J Clin Oncol 8: 118-120, 2003.

10. Weiss K, Köck HH, Atefie K and Sinzinger H: Complete scintigraphic lesion regression after single 153Sm-EDTMP therapy in prostate cancer. Rev Esp Med Nucl 20: 311-312, 2001.

11. Ameur A, Touiti D, el Mostarchid B, el Alami M, Jira H and Abbar M: Brain metastasis of prostatic cancer: regression under hormonal treatment. Prog Urol 11: 1298-1301, 2001 (In French).

12. Gayet $\mathrm{R}$ and Curtillet $\mathrm{H}$ : Regression of pulmonary metastases from prostatic cancer after treatment with estrogens. J Urol Nephrol (Paris) 80: 709-715, 1974 (In French).

13. Turner $\mathbf{J}$ and Chaudhary U: Dramatic prostate-specific antigen response with activated hemicellulose compound in metastatic castration-resistant prostate cancer. Anticancer Drugs 20: 215-216, 2009.

14. Lundgren R: Flutamide as primary treatment for metastatic prostatic cancer. Br J Urol 59: 156-158, 1987.

15. Delaere KP and Van Thillo EL: Flutamide monotherapy as primary treatment in advanced prostatic carcinoma. Semin Oncol 18 (5 Suppl 6): 13-18, 1991.

16. National Comprehensive Cancer Network: The NCCN clinical practice guidelines in oncology 2011: prostate cancer version 1: clinical practice guidelines in oncology. http://www.ncen.org/ professionals/physician_gls/pdf/prostate.pdf. Accessed Jan 12, 2013. 
17. Ohlson N, Bergh A, Nygren K, Stattin P and Wikström P: The magnitude of early castration-induced primary tumour regression in prostate cancer does not predict clinical outcome. Eur Urol 49: 675-683, 2006

18. Shelke AR and Mohile SG: Treating prostate cancer in elderly men: how does aging affect the outcome? Curr Treat Options Oncol 12: 263-275, 2011.

19. Feldman BJ and Feldman D: The development of androgen-independent prostate cancer. Nat Rev Cancer 1: 34-45, 2001.

20. Taplin ME, Bubley GJ, Shuster TD, Frantz ME, Spooner AE, Ogata GK, Keer HN and Balk SP: Mutation of the androgen-receptor gene in metastatic androgen-independent prostate cancer. N Engl J Med 332: 1393-1398, 1995.

21. de Bono JS, Logothetis CJ, Molina A, Fizazi K, North S, Chu L, Chi KN, Jones RJ, Goodman OB Jr, Saad F, et al; COU-AA-301 Investigators: Abiraterone and increased survival in metastatic prostate cancer. N Engl J Med 364: 1995-2005, 2011.

22. Scher HI, Halabi S, Tannock I, Morris M, Sternberg CN, Carducci MA, Eisenberger MA, Higano C, Bubley GJ, Dreicer R, et al; Prostate Cancer Clinical Trials Working Group: Design and end points of clinical trials for patients with progressive prostate cancer and castrate levels of testosterone: recommendations of the Prostate Cancer Clinical Trials Working Group. J Clin Oncol 26: 1148-1159, 2008.

23. Bubley GJ, Carducci M, Dahut W, Dawson N, Daliani D, Eisenberger M, Figg WD, Freidlin B, Halabi S, Hudes G, et al: Eligibility and response guidelines for phase II clinical trials in androgen-independent prostate cancer: recommendations from the Prostate-Specific Antigen Working Group. J Clin Oncol 17: 3461-3467, 1999.

24. Nayyar R, Sharma N and Gupta NP: Prognostic factors affecting progression and survival in metastatic prostate cancer. Urol Int 84: 159-163, 2010.

25. Collette L, de Reijke TM and Schröder FH; EORTC Genito-Urinary Group: Prostate specific antigen: a prognostic marker of survival in good prognosis metastatic prostate cancer? (EORTC 30892). Eur Urol 44: 182-189, 2003.

26. Hussain M, Tangen CM, Higano C, Schelhammer PF, Faulkner J, Crawford ED, Wilding G, Akdas A, Small EJ, Donnelly B, et al Southwest Oncology Group Trial 9346 (INT-0162): Absolute prostate-specific antigen value after androgen deprivation is a strong independent predictor of survival in new metastatic prostate cancer: data from Southwest Oncology Group Trial 9346 (INT-0162). J Clin Oncol 24: 3984-3990, 2006.
27. Johansson JE, Sigurdsson T, Holmberg L and Bergström R: Erythrocyte sedimentation rate as a tumor marker in human prostatic cancer. An analysis of prognostic factors in 300 population-based consecutive cases. Cancer 70: 1556-1563, 1992.

28. Scher HI, Jia X, de Bono JS, Fleisher M, Pienta KJ, Raghavan D and Heller G: Circulating tumour cells as prognostic markers in progressive, castration-resistant prostate cancer: a reanalysis of IMMC38 trial data. Lancet Oncol 10: 233-239, 2009.

29. Goodman OB Jr, Symanowski JT, Loudyi A, Fink LM, Ward C and Vogelzang NJ: Circulating tumor cells as a predictive biomarker in patients with hormone-sensitive prostate cancer. Clin Genitourin Cancer 9: 31-38, 2011.

30. Vishnu P and Tan WW: Update on options for treatment of metastatic castration-resistant prostate cancer. Onco Targets Ther 3: 39-51, 2010.

31. Molassiotis A, Fernadez-Ortega P, Pud D, Ozden G, Scott JA, Panteli V, Margulies A, Browall M, Magri M, Selvekerova S, et al: Use of complementary and alternative medicine in cancer patients: a European survey. Ann Oncol 16: 655-663, 2005.

32. Lin YH, Chen KK and Chiu JH: Coprescription of chinese herbal medicine and Western medications among prostate cancer patients: a population-based study in Taiwan. Evid Based Complement Alternat Med 2012: 147015, 2012.

33. Lin YH, Chen KK and Chiu JH: Use of Chinese medicine among prostate cancer patients in Taiwan: a retrospective longitudinal cohort study. Int J Urol 18: 383-386, 2011.

34. Wang L, Zhou GB, Liu P, Song JH, Liang Y, Yan XJ, Xu F, Wang BS, Mao JH, Shen ZX, et al: Dissection of mechanisms of Chinese medicinal formula Realgar-Indigo naturalis as an effective treatment for promyelocytic leukemia. Proc Natl Acad Sci USA 105: 4826-4831, 2008.

35. Lam W, Bussom S, Guan F, Jiang Z, Zhang W, Gullen EA, Liu SH and Cheng YC: The four-herb Chinese medicine PHY906 reduces chemotherapy-induced gastrointestinal toxicity. Sci Transl Med 2: 45-59, 2010.

36. Liang HL, Xue CC and Li CG: Regression of squamous cell carcinoma of the lung by Chinese herbal medicine: a case with an 8-year follow-up. Lung Cancer 43: 355-360, 2004.

37. Cheng HM and Tsai MC: Regression of hepatocellular carcinoma spontaneous or herbal medicine related? Am J Chin Med 32: 579-585, 2004.

38. Scher HI and Kelly WK: Flutamide withdrawal syndrome: its impact on clinical trials in hormone-refractory prostate cancer. J Clin Oncol 11: 1566-1572, 1993. 